\title{
Chapter 15 \\ Educating Toward a Culture of Peace Through an Innovative Teaching Method
}

\author{
Silvia Guetta
}

\subsection{Introduction to the Education Program}

This chapter presents a peace education program carried out with more than 70 students in a high school in Florence, Italy, during the 2016-2017 school year. Educational activities were conducted outside the school environment and hours. Nevertheless, they were part of the curriculum and previously agreed upon with the school teachers. Liaisons for the project were the Florence UNESCO Center ${ }^{1}$ and the Chair of Pedagogy for Conflict Management of the Department of Education and Psychology of the University of Florence. The main objectives of the program were to conduct research into the meaning of peace and to promote cultural diversity in accordance with the principles and the values endorsed by UNESCO. Therefore, we chose to follow the Peace Education Program of Prem Rawat Foundation (FPEP).

To outline the context of the program, this chapter will first present relevant models of peace education, briefly discussing the importance attributed to this type of education by the school system through which the activities took place. The education program was implemented by the school as part of their efforts to reduce the escalation of violent behaviors. It was considered an opportunity to make students take responsibility for their actions through a focus on dialogue, which is seen as a relational tool enabling the creation of a bond between personal, worldview, feelings, life plans, creativity, and individual resources. Moreover, there was a need for students to discover and understand language and behaviors related to a non-violent style of communication (Rosenberg, 1998) and to open new horizons of meaning in terms of interpersonal, intrapersonal, and intergroup relationships. The program was designed to help students explore their own and others' social and communi-

${ }^{1}$ www.centrounescofi.it

\footnotetext{
S. Guetta $(\bowtie)$

University of Florence, Florence, Italy

e-mail: silvia.guetta@unifi.it
} 
cation skills and through this to discover a new lexicon and vocabulary for communicating.

The educational goals included development of a more complex perception of actions and behaviors seen in school and outside; discovery of students' innate resources such as hope, choice, and appreciation ${ }^{2}$; and decentering one's thoughts and emotions in order to address problems from other people's perspectives. The reflection on the circularity of one's own feelings, thoughts, and behaviors, and the capacity to view everyday problems in a positive, empathic, and creative way, was expected to help students learn to be less reactive and more proactive.

The description and explanation presented here will help readers understand how the peace education program developed by the Prem Rawat Foundation was adapted to this target audience of students and how values of cultural diversity recommended by UNESCO were integrated. Furthermore, it will clarify how students were encouraged to initiate an inner dialogue and the process of self-discovery in order to improve their sense of well-being and their relationships with others.

In this brief exposition, the author analyzes various aspects of the program and its impact. First, she considers how this contribution advances UNESCO's recommendation to foster development of a culture of peace. Second, she explains the methodological approaches used in the project. Third, she details the monitoring and evaluation criteria used to assess achievement of the educational goals, and finally, she discusses whether the students considered the experience to be truly lifechanging and educational.

It should be clarified that the training pathway to peace developed in this project was part of a wider educational campaign. The project involved three target groups: 70 high school students, about 200 university students from 2 different academic programs, and about 30 teachers working in various fields and in different school grades throughout Tuscany, Italy. It was an ambitious project, supervised by the author. The program was meant to promote education for citizenship, which was considered important by Florentine politicians as part of the international event "UnityinDiversity. ${ }^{3}$ " The contents, workshop approach, and most of the methodologies were shared by the three target groups. Locations, facilitators, and timetables were scheduled according to the training needs of the groups. The contents of the course, adapted from "Prem Rawat's Peace Education Program,"4 was organized into ten modules, which through the use of videos, readings, and a workbook investigate the ten keywords for peace: peace, appreciation, inner strength, self-awareness, clarity, ability to understand, dignity, choice, hope, and happiness.

Three trainees with previous knowledge of the topic led activities for the high school students. The training program lasted a total of 24 hours, delivered in 2-hour meetings twice a week. The workshops took place in a social co-op with long-term

\footnotetext{
${ }^{2}$ Prem Rawat, https://www.tprf.org/wp-content/uploads/.../getting_started.pdf

${ }^{3}$ UnityinDiversity 2016 http://www.unityindiversity.it/conference/program; https://www.youtube $. c o m /$ watch $? v=4953 I l t 62 U 8 \& \mathrm{t}=0$ s\&index $=23 \&$ list=PLQwEJh6E8bRQkn7iDNcgurRL31F GrrgJY

${ }^{4}$ https://www.tprf.org/programs/peace-education-program/
} 
experience in the social inclusion of people with disabilities and people from other countries and backgrounds. The education program concluded with two public events, the first organized by the university and the second held in the offices of the Municipality of Florence. The goal of the first event was to present and discuss the results of the program in terms of educational gains and outcomes realized by the three target groups. The second event was a meeting open to the public and local and national governmental authorities at which the results were presented and recommendations of best practices for peace education were made.

\subsection{Peace Education in Italy: An Overview}

It was only in the mid-1940s, after the catastrophe of World War II, that several Italian education specialists began wondering about the necessity of schools promoting peace education. Maria Montessori (1949) was the first to incorporate peace education into her educational activities. She based her approach on the observation that societies invest resources, time, money, research, and relationships into educating for war and conflict, even though wars do not bring wealth, success, growth, or happiness. Despite widespread awareness of this, people have not been able to abandon educational models that convey knowledge through coercion, punishment, marginalization, and discrimination.

According to Montessori, "education is the weapon of peace, which will forge men and women of peace" (Montessori, 1949, p. 43). In Italy, awareness of the necessity of a real and tangible commitment to a future based on coexistence, respect for human rights, and dialogue dates back to the 1950s and 1960s, when people not directly involved in the educational field, but associated with various disciplinary sectors, began questioning and engaging in a search to determine the deficiencies of the educational models of the time. They determined that these models were not promoting students' independence, active learning, autonomy, self-determination, or freedom of speech. Between the 1960s and 1980s, many intellectuals delivered speeches and lectures and published books and articles in order to raise awareness and influence public opinion - especially among people working in the educational field -about the importance of education based on cooperation, non-violence, and human rights. Yet, for many years, their arguments were largely ignored. The general public began recognizing the importance of peace education only toward the end of the 1990s, when Italy faced a perceived social and cultural emergency due to immigration, and political control of internal violence was achieved.

It is not possible to cover the conspicuous contributions of all of those who, in a variety of ways, outlined the educational pathways aimed at creating individuals capable of respecting human rights, avoiding all forms of violence and social or cultural oppression, and rejecting military ideals. Until recently, these contributions, while made by important and enlightened intellectuals, were exclusively expressions of the male world. Women's voices were not heard until the twenty-first century. 
Peace, as the opposition to the consequence of war, has been managed by men. The syllogism was that because who go to war assume a man's duty, and implicitly their social mandate, to make peace. A reflection on the connection between peace education and gender issues remains an almost unexplored research field today. The reference models and theories are linked to a negative understanding of peace; the idea that defense and safety can be achieved only through the use of weapons is still widespread. History is the only field in which research on women's positions, attitudes, and awareness regarding wars and reconstruction processes has been welldeveloped. In any case, pacifist positions, and social and cultural engagements, in which women gather and support channels of dialogue and participation, have not been acknowledged to the same extent as the ones supported by male intellectuals (Bartoloni, 2017). Generally speaking, there is a parallel between the scant regard paid to women's efforts to support non-violence and to oppose war and the lack of acknowledgment of their commitment and noble resistance.

Among those who raised their voices against injustice, inequality, discrimination, exclusion, and poverty, three examples stand out: Lorenzo Milani (1923-1967), Danilo Dolci (1924-1997), and Alberto L'Abate (1931-2017). Lorenzo Milani was one of the most unusual personalities of the Catholic world. Opposed to any kind of hierarchy, which he considered meaningless and rife with abuse and oppression, he was the first intellectual to launch a debate regarding obedience, military service, and the methods used by the school system that educate students to exclude the poor and the social outcasts, rather than helping them. As a punishment for his outspokenness, Milani was forced to leave the city and was assigned to a remote school in the Tuscan hills of the Mugello area. There, he demonstrated how belief in freedom, respect for human dignity, and the right to education were the real cornerstones of knowledge that could foster emancipation. Milani established the famous popular School of Barbiana. He believed that being good men was more important than being good Christians. To him, being good men meant walking with dignity in the world, having culture, professionalism, and, especially, awareness (Milani, 1967). The school created by Milani was a real workshop of education for non-violence, in that it represented an absence of violence (Panerai, Vitaioli, \& Nicola, 2012). Like Freire (1971), Milani addressed his educational work to the members of the lowerworking class, in order to make them aware of their condition and of the possibility for change. He acted as a consciousness-shaping agent, creating a context that made it possible to experiment with a variety of interpersonal relationships in which the ruler-ruled hierarchy was questioned and deconstructed. He did not view the rural and mountain cultures as expressing a lower or marginalized form of knowledge. An overview of Milani's ideas, modeled on the daily educational and school experiences of the popular School of Barbiana, is outlined in the pages of two important works: Pastoral experiences (1958) and Letter to a teacher (1967).

Danilo Dolci developed Gandhi's ideas and actions of non-violence. Dolci outlined an active method of peace education: the reciprocal maieutic approach. Known as the Sicilian Gandhi, he developed his educational method inside a generic program, whose pillars were non-violent direct action to raise public awareness, such as fasting, parades, committees, protests, and popular self-analysis sessions. Dolci 
did not consider peace as the absence of conflict, but rather as the "capacity of renewing, building, fighting, winning in an innovative way: it is health, fullness of life [...] a different approach to life" (Dolci, 1972, p. 84).

Dolci's method is suitable for adults or children and can be used in schools and in non-formal education programs. It is based on Socratic philosophy, which focuses on stimulating learners and helping them reach their full potential. The setting is a dialogue-based workshop, in which creativity, problem-solving, and awareness of one's own knowledge are encouraged. During this dialectic educational experience, the role of the researcher/facilitator/mediator is to support the improvement of knowledge and skills of every member of the group. The goal is to develop a participatory means of defining solutions to social, economic, and environmental problems caused by violence and policies of exclusion ${ }^{5}$ and to create a maieutic process to shape a society based on dialogue (Galeazzi, 1992). ${ }^{6}$

Over the years, it has become clear that only a study of the causes of wars and of the conditions for peace, supported by an accurate interdisciplinary investigation, can provide ideas, tools, and concepts necessary to train professional educators and peace operators (Panerai, Vitaioli, \& Nicola, 2012). As L'Abate said, "research helps to increase our knowledge and evaluate our acts; training helps to get prepared for new tasks that might arise from research work and action helps to push forward those steps considered necessary to modify or improve the current situation" (L'Abate, 2001, p. 49). Alberto L'Abate disseminated his passion for peace to multiple generations of students through technical work, field research, and action in times of crisis and armed conflict. L'Abate strongly believed that violence is a cultural superstructure and that economies would benefit from funding and promoting peace. For this reason, he strove to reveal the political interests fostering injustices and destruction. L'Abate first introduced to Italy Galtung's ideas, research, and commitment to non-violence (Galtung, 1996). A pioneer of peace studies in Italy, L'Abate and his colleagues from various disciplines designed an original and innovative study course. In 2001, along with Giovanna Guerrieri, he founded the degree course in "Peace Operators." The course was a cooperative effort between the departments of sociology, pedagogy, medicine, and political sciences. His courses on peace research methodology illuminate the bond between theory and practice, research and intervention, and how they can support peace studies. Connecting theory and practice allows one to go beyond the abstract nature of theory, giving birth to a revolutionary and non-violent reality. He believed that the first step toward successful change was deconstructing cultural models that passively operate within

\footnotetext{
${ }^{5}$ Danilo Dolci's experience took place in Sicily, where he has close social bonds, especially with the disadvantaged and oppressed populations marginalized by society. Studying the ways in which people could change social, economic, and political conditions of that area in order to drive changes from the bottom, by working on people's potentiality for a democratic and social redeeming, can be considered as one of the best paths to follow if we wish to educate to peace.

${ }^{6}$ Many contributions paved the way to new possibilities of interpreting peace education in the 1960s and 1970s. It is not possible to mention here the copious authors that have worked and written on this theme. For further information, see Panerai, Vitaioli, and Nicola (2012) and Galeazzi (1992).
} 
us and that we often unconsciously convey in our interpersonal relationships. For him, real revolution occurs first inside people and only afterward in social structures. All of this will be a reference point for the development of professionals working in various international peace-related fields and contexts.

\subsubsection{Proposals for Peace Education}

Beginning in the 1990s, the main social issues in Italian schools concerned the field of intercultural education. Scholars in the field of education and teachers in compulsory schools (for students aged 5-16) have focused on the creation of innovative educational practices, such as the inclusion of migrant children, teaching the Italian language to foreign students, ensuring educational success to those coming from other educational environments, and respecting diverse traditions, knowledge, and habits.

New fields of study regarding relationships in schools have been explored, such as tolerance, cultural integration, and inclusion. The proposal for intercultural education, which began with the inclusion of migrant children, addresses the way people deal with the "other" and those who are different, leading to a more positive image of the foreigner. In the past, foreigners were seen as needy, coming from disadvantaged, exploited areas plagued by poverty and wars. Education has encouraged a more compensative pedagogy, promoting cultural differences as an opportunity for gaining broader knowledge of the world.

Moreover, Italian pedagogy has created its own model of intercultural education from practical experience in schools. The theoretical reflection based on research, investigation, and projects came out clearly only at the end of the 1990s. At first, the presence of foreign children in schools was considered a social emergency. In particular, three socio-educational issues required a prompt solution: the migration of people from geographically, socially, and culturally different areas; a resurgence of racism and xenophobia leading to exclusion and violence; and the crisis of the models of democratization that appeared after the fall of the Berlin Wall (1989).

In the 1990s, philosophers, education specialists, anthropologists, psychologists, and intellectuals from various fields (Cambi, 2001) introduced a pedagogical paradigm of difference, addressing different types of diversity, including disability, ethnicity, culture, and gender. Recent decades have witnessed a debate on difference, starting with gender-based difference. This has allowed people to rethink education, sciences, and pedagogy, by organizing and considering education programs that address diversity. The new sociocultural mosaic outlines an "affirmation of the difference as structure and value of education in the contemporary world [that] implies the construction of a new model of subject, a new idea of culture and, finally, the theorization of a different kind of society. Elements characterized by structures/ programs and tasks that differ from those elaborated during the historical period ruled by identity" (Cambi, 2001, p. 53). 
At the beginning of the millennium, the new pedagogical issues stimulated by the debate on intercultural education partially merged into peace education. This involved the search for participatory and cooperative teaching methods that enable the creation of an inclusive learning environment. Methodological approaches, such as cooperative learning, peer education, and participatory action research, support the deconstruction of educational perspectives based on the control-based, asymmetrical relationship between teacher and student. They encourage the discovery of learning processes based on awareness, relational interdependence, self-help, and overcoming of obstacles due to linguistic differences. The relationship between native languages and teaching and learning the Italian language has been one of the primary fields of research and experimentation since Italian schools became more multicultural.

It is important to mention that in some settings, experiments have been undertaken to create experiences of active citizenship and awareness about the system of legal rights, which offer educational paths based on the reciprocal maieutic approach (Pazzi, 2018). Their goal is to provide knowledge in mediation, management, and resolution of conflicts (Novara, 2011; Sclavi, 2007).

In the last decade, a new socio-educational emergency has emerged, characterized by an increase in violence inside and outside of schools. There are numerous social and cultural causes behind these episodes, including poverty, exclusion, transmission of violent educational models, the search for simple and immediate solutions to complex and deep problems, disintegration of the social network of solidarity and ethical responsibility, and the loss of shared community values. These events have reiterated a purely "school-based" need for peace education.

Over the last few years, schools have tried various ways to address this crisis. In 2017, the Italian Ministry of Education has published the Guidelines for peace education and glocal citizenship. ${ }^{7}$ The opening title of the document "Peace can be taught and learned" demonstrates how little attention is allotted to the vital maieutic dimension of feeling and experiencing peace as a life opportunity, a flourishing condition, and a personal pursuit which all people desire for themselves and their loved ones. The document clarifies that this is not a new subject or teaching area, since peace education has to be considered as "the integrating background of the whole educational process" (Italian Ministry of Education, 2017, p. 18).

This does not mean that since "everything is peace," we should not do anything differently. Peace, and especially the experience of its absence, pushes us to constantly rethink our state of mind and our teaching style (Italian Ministry of Education, 2017, p. 16). Following the perspective of positive peace, the guidelines state "Educating about peace means learning to live together in peace, without wars or violence, constantly promoting the respect of dignity and of every person's fundamental rights, acknowledging and appreciating differences. For these reasons, peace education covers every area of education, links them and integrates them in a constructive way" (Italian Ministry of Education, 2017, p. 16).

\footnotetext{
${ }^{7}$ Guidelines for peace education and glocal citizenship http://www.miur.gov.it; http://istruzione. umbria.it/news2017/miur/pace/LineeGuidaPaceCittadinanza.pdf
} 
Due to the need to constrain violence in schools, there is a movement to include in the school curricula themes related to conflicts and their management, rather than their prevention. This necessitates definition of the skills required to educate individuals who live in areas of conflict, so they can prevent conflicts from becoming situations of extreme violence. Conflicts may be considered an important relational experience, since they enable people to experiment and learn verbal and nonverbal communication strategies to save a relationship between stakeholders with different goals and to find solutions to problems.

As a result of the increase of educational contributions related to understanding the evolving nature of conflicts and possible ways to mediate and manage them, a new teaching perspective has developed. This has enabled a deeper understanding of teachers' interdisciplinary and transdisciplinary perspectives but is often criticized and inaccurately portrayed in the media for its assumed fragmentation of learning and knowledge.

\subsection{Peace and Peer Education: A Proposal}

In view of all this, the author and her collaborators organized round table meetings with local associations, schools, and the University of Florence. There was a demonstrated need for a training program targeting high school students that provided them with the tools to express, understand, and interpret their needs and knowledge and helped them discover how to recast their needs to achieve more peaceful relationships by using appropriate language, emotions, and cooperative planning. The contribution made by theoretical reflection and new methodological approaches underlines the necessity of peace- and person-centered educational planning choices. The emphasis is on how change in thoughts, feelings, lifestyle and behavior spring from the self, rather than from external actions. The proposal advocates taking responsibility, an obligation which teenagers seldom have the chance to explore in an enriching and constructive way.

School and training programs in general tend to be based on external behavioral and communicative factors. Little room is left for investigating the inner driving force that pushes people to activate peaceful practices or actions. In this context, both the reciprocal maieutic approach and the routes toward inner peace based on Gandhi's model (Pontara, 1996) prove useful. The quest for inner peace promoted by Prem Rawat's model is appropriate for students, as it provides them with an effective yet complex path to peace rather than violence. This choice starts within oneself, the awareness of and responsibility for our actions that puts our perceptions and feelings into practice. The pathway to peace education is outlined through a search for inner peace using the key concepts suggested by Prem Rawat. ${ }^{8}$

Working with students aged 15-16 requires exploring patterns of reciprocal exchange and points of view. Dialogue with young people underlines their need to

${ }^{8}$ Rawat, PEP facilitator 
find ways to protect themselves and not let the overwhelming violence in the media affect them and create a sense of disempowerment or loss of empathy. Building inner peace helps individuals identify their strengths, build a solid foundation, and avoid surrendering to those who provide quick solutions. Choosing inner awareness requires patience, empathy, and sharing and is challenged by current events and people who consider caring an outlook that cares for all humankind to be pointless.

Developing inner peace becomes a way to increase personal well-being. This kind of program helps young people realize they are increasingly responsible for their own well-being and success. Teenagers' needs for freedom, independence, and autonomy in making life-choices enhance this process. To gain an accurate idea of the described program, it is important to understand that the educational project to increase self-awareness embraces educational innovations promoted by the Italian law La Buona Scuola of July 13, 2015, Nr. 107. ${ }^{9}$ Of particular relevance are the regulations outlining the compulsory design of schoolwork programs during the last 3 years of high school. Similar programs should be created based on agreements between schools and other entities (companies, firms, associations) in which students will carry out their training. Schoolwork programs can be valuable training opportunities for students, because they increase students' knowledge and shape their values, self-esteem, self-confidence, and motivation to learn. Relational and communicative relationships outside school enable them to experience previously unexplored personal skills. Schoolwork programs also provide important paths toward social inclusion for migrant students, enabling them to experience different kinds of relationships and acceptance from what they experience at school. These programs might also be positive for students at risk of leaving school early, since new relational and training opportunities encourage them to use more problemsolving techniques and in a more determined way. It also pushes them to explore creative solutions, establish mediation and negotiation procedures, and be decisionmakers. In other words, it helps them to become more capable of making choices, even with only partial information, thus developing their self-esteem. ${ }^{10}$

\subsubsection{Context and Contents of the Education Program Aimed at Peace and Cultural Diversity}

The schoolwork program, The value of cultural diversity as a key asset for human development towards a culture of peace among citizens, is part of the regulatory framework outlined by Buona Scuola (whose name is translated as "good school"). Moreover, it stems from the increased interest in cross-cultural issues and conflict management in schools.

\footnotetext{
${ }^{9} \mathrm{https} / / /$ labuonascuola.gov.it/ articles 33 to 43 .

${ }^{10}$ Ibidem
} 
The training program was carried out during the 2016/2017 academic year. It involved over 70 students from the Machiavelli Capponi Language High School of Florence. For the sake of adapting to the school guidelines and regulations concerning the schoolwork alternation activities, the number and length of meetings were reduced. Therefore, in line with Prem Rawat's PEP-2, ${ }^{11} 12$ 2-hour-long workshops were designed. Each session lasted about 35 minutes and featured introductory videos. This change was made to make the program more suitable to an audience of all ages, including young people. This program is highly recommended for people who find it hard to concentrate for long periods of time and who are being introduced to these issues for the first time. ${ }^{12}$

In line with the PEP handbook, the activities include videos that present the topic, further readings, and the use of a notebook in which participants are encouraged to write down their thoughts, perceptions, moods, and inner experiences that are being explored. The material presented does not include any specific cultural or religious content. The thoughts and emotions that are stimulated, made explicit, and discussed allow each participant to understand how he or she feels and acts regarding peace and core life values. This process recognizes that people are diverse but the search for meaning in life is universal.

Prem Rawat says that within each one of us lies a natural tendency to be satisfied: "Within all people lies an inherent thirst to be content" (Rawat, 2015, p. 11). Despite being a deeply personal and intimate message, this is the basis for global peace. The idea that the culture of peace comes primarily from within ourselves is crucial in the speeches of Prem Rawat. However, there are several references to a highly conflicted, external social dimension, which affects the inner personal dimension. The macro dimension is represented by conflicts between people and nations. An intermediate dimension is generated in intergroup and interpersonal scenarios. The micro dimension is the conflict that arises within an individual. This is the most important conflict, as it triggers a chain reaction that leads to conflicts on the other two levels (Rawat, 2015). According to Rawat, individual responsibility is an opportunity to practice inner peace, as well as to defuse this process and create peace around ourselves.

In the videos, Prem Rawat does not diversify the content according to the environment or the audience. Prem Rawat starts from the assumption that humans are not very different from each other. Therefore, this universal message will be interpreted according to the meanings specific to each recipient. As Rawat says, building a moral base that supports peace cannot come from outside; it must come from a

\footnotetext{
${ }^{11} \mathrm{Http} / / /$ it.theypi.net/prem-rawat.php. The aim of the Peace Education Program (PEP) is to help participants discover their own inner resources: innate instruments allowing for a better life, such as fortitude, the ability to choose, hope, and the possibility of attaining personal peace. The educational program includes ten videos, each focusing on a specific topic. This material made it possible to design individual academic modules or interactive and customized seminars for different types of participants. The topics are based on excerpts from speeches given by Prem Rawat around the world including peace, appreciation, inner strength, self-awareness, clarity, ability to understand, dignity, choice, hope, and happiness.

${ }^{12} \mathrm{https}: / /$ www.tprf.org/programs/peace-education-program/
} 
moral unity, shared by all human beings, that comes from listening to oneself through the so-called breath of life. Inner peace can be found in any life situation, even in the most extreme ones, such as prisons or armed conflicts. This fosters the hope that, despite living in a world threatened by weapons that could destroy us all in a matter of seconds, there is solidarity and the awareness of belonging to the same species (Balducci, 1985). All this brings us to consider a planetary perspective and a new form of humanism: planetary humanism (Orefice, 2003). It involves the recognition that, despite differences, we share a potential precisely because we all belong to the same species. Therefore, the first thing to do is to nourish the peace in our hearts.

From this perspective, it becomes easy to understand how every human has the right to experience peace, although in our culture this is far from obvious. Considering peace as a human right opens up areas for research and analysis on the issues of rights, duties, responsibilities, and actions. These are important learning goals for young people, who are invited to elaborate on the considerations discussed in the workshops by contextualizing the definitions through interdisciplinary sources. For example, the principle that peace is a right is linked to Article 28 of the Universal Declaration of Human Rights (United Nations, 1948), which establishes that "Everyone has the right to social and international order, one that allows the rights and freedoms stated in this Declaration to be fully realized". ${ }^{13}$ The article does not explicitly address peace as a right, but it requires states to commit themselves to promoting the appropriate conditions, thus renouncing to the right to wage war through disarmament, educating to respect rights, establishing a Civil Peace Service, and not obtaining atomic bombs or hosting foreign military bases. In addition, UN Resolution 33/73 (1978) ${ }^{14}$ codifies the "right of an individual to live in peace" (Milanese, 1992). In 1984, Resolution 39/11'15 (the Declaration on the Right of Peoples to Peace), with a simple text, declared the "sacred right to peace of every individual and people."

In recent years, the UN Human Rights Council has adopted the Promotion of the right to peace (2015) resolution, which reiterates the concept by stating that peace is a "universal, indivisible, interdependent and interrelated" right, which takes place without any kind of discrimination.

\subsubsection{Cooperation in Education and Learning by Doing}

After clarifying the rationale and general structure of the project, we now look at how the work was organized, the original aspects of the experience, how the program was assessed, and the strengths and weakness that emerged. As mentioned above, it was in our interest to integrate the educational models of peer education

\footnotetext{
${ }^{13} \mathrm{http}: / /$ www.ohchr.org/EN/UDHR/Pages/Language.aspx?LangID=itn

${ }^{14} \mathrm{http}: / /$ www.un.org/documents/ga/res/33/ares33r73.pdf

${ }^{15} \mathrm{http} / / / \mathrm{www}$.ohchr.org/EN/ProfessionalInterest/Pages/RightOfPeoplesToPeace.aspx
} 
and the educational maieutic method with the inputs and the instruments developed by Prem Rawat.

A diverse work group was created to organize the student workshops and included the author, a representative of the Prem Rawat Foundation, a PhD student, four interns, and three undergraduate students from the course for professional educators. The entire group participated in the activities prior to the completion of the course, ${ }^{16}$ carefully studied the materials, took part in training, and joined discussions about the content. A self-training path contributed to making the group more cohesive and interdependent and enabled the design of activities that were engaging and empathetic. The group posed hypotheses about the doubts and questions the students might have and offered solutions for critical cases students might identify. It also adapted the program to the needs, motivations, and learning pace of the younger participants. Awareness of the care given to the working group was instrumental in the success of the meetings with the students. This, in turn, helped clarify the meaning of the interpersonal relationships.

The group included a range of student representatives (interns, undergraduates, and $\mathrm{PhD}$ students). Learning-by-doing practices were introduced to help in the construction of knowledge and educational skills. Specifically, the three interns organized the meetings with the high school students, and one of the interns was responsible for coordinating the development of the courses and arranging the final days of the program (May 19, 20, and 21). The three undergraduate students acted as activity observers, and a representative from another university involved in a similar project met with the group to compare experiences. As part of the selfeducation course, six meetings were devoted to sharing the proposal, training interns and facilitators, defining the observation model, and discussing the evaluation criteria. One of the strengths of the design group was to be the bearer of a multitude of contexts that allowed adoptions of a decentralized, maieutic, and inclusive education approach.

From the beginning of the collaboration, each student contributed to the project sharing their skills and opinions, in a spirit of cooperation, thus allowing for critical reflection, practicing listening skills, and strengthening of self-esteem. An exchange of ideas and opinions helped shape the operators involved in the project. The diversity of facilitators ensured that during the training and planning phases, those who participated would broaden their thinking and bridge between people. This, in turn, allowed participants to explore distant life contexts, where the meaning of peace and its related quest took on unprecedented meaning.

To better adapt the Prem Rawat program to the students' training environment, the recommendations of the facilitators were followed. The facilitators prepared for each session by familiarizing themselves with the content of the videos and readings, but the course content was at times paused to allow reflection and mutual listening and sharing of insights on issues such as diversity; social, cultural, historical, geographical, and gender identity and belonging. The facilitators gave each

${ }^{16}$ January-March 2017. 
participant a notebook to write down their thoughts, concerns, emotions, questions, and readings that complemented their reflections.

The inputs provided by the program for peace and the trainees' commitment to train more than 70 students in a schoolwork program contributed to an understanding of how to engage in open dialogue starting from personal experiences to discussing wars, conflicts, cultural diversity, and comprehensive research to ensure everyone has a right to peace. This created daily opportunities for discussion, that are generally difficult to find in university contexts, and allowed for a firsthand assessment of how our educational environment measure up in terms of this type of thinking, feeling, and creativity.

The organizational aspect was crucial for the trainees. It required extensive synergy with daily school activities and administration and necessitated different ways of relating to students' learning. The activities included meetings and workshops, distribution of materials, arranging for use of spaces and equipment, and screening of videos. Moreover, it was important to facilitate participants' reflections and identify indicators to assess the process.

The facilitators were close in age to the students and had tangible experience in peer education. Their role as peer teachers/facilitators made the experience an open discussion, free of any reverence and fear. A dialogue began with the questions posed by the students and exchange of experiences, which at times were difficult to share. Peer education integrated with the maieutic approach and the learning-bydoing process (also useful for the trainees, who improved their educational skills) favored the building of social and empathic skills. The course content facilitated an awareness of being more attentive to one's own needs and other people's needs, as well as putting more trust in feelings and personal choices.

Workshop attendance and active participation in the discussions were monitored and served as process indicators. Participants' regular attendance was essential, partly because the PEP, by facing topics involving personal motivation and choice, calls for elaboration of a multitude of emotions and thoughts that can be better understood and contextualized if they are processed immediately. ${ }^{17}$ At the end of the process, the facilitators also followed the PEP manual checklist and compared their findings with those of the observers. ${ }^{18}$

Other indicators were shared with the teachers who followed the schoolwork program, including an assessment of the ability to report what was done during the workshops and an observation of relational changes within the group. The final outputs, written materials, and questionnaires conducted during training made evaluating the process more tangible. At the end of the workshops, participants were asked to design and implement (individually or in small groups) something that expressed one or more messages of peace. There were no limits or default structures. Examples include songs or poems, video interviews, and power point presentations. ${ }^{19}$

\footnotetext{
${ }^{17}$ https://www.tprf.org/wp-content/uploads/.../role_facilitator.pdf, p. 3.

${ }^{18} \mathrm{https} / / / \mathrm{www} . t p r f . o r g / \mathrm{wp}-$ content/uploads/.../role_facilitator.pdf, p. 7.

${ }^{19} \mathrm{https}: / / \mathrm{www}$. semidipace.space/
} 
This final step of the process was carried out partly with the facilitators and partly at school. It consolidated the laboratory experiences, summarized and finalized the discussions, and developed awareness that when one person's ideas meet other people's ideas, the necessary strength to build new scenarios can be acquired. The creation of outputs and the presentations during days of self-assessment and local meetings ${ }^{20}$ were not included in the Prem Rawat program. They were welcomed with interest, applause, and full approval by both local and national institutions. ${ }^{21}$

\subsection{Conclusions}

The program was evaluated according to the following indicators: observations by undergraduate students during the workshops; organization of the three final days consolidating the experience of the groups; sharing with locals the innovative concepts raised by the experiences; description of various types of outputs created by the participants; open comments on the questionnaires distributed at the end of the program; reflections and observations written by students in their notebooks; and the changes in the relationships observed by high school teachers.

The positive evaluation given by the school trainers and other professional trainers who participated in the three final days were used to assess the educational path to peace and cultural diversity. Observations made by undergraduate students suggested that the participants' attendance was regular, despite the meetings being held at a venue far from their schools. The participants made a fair contribution to the proposed topics, and their ability to elaborate on the course contents increased. Students were willing to be guided and oriented so as to know themselves better, clarify and identify their feelings, and accept new perspectives, even if they were conflicting or unusual. All observers also commended the work carried out by the facilitators.

The observations also indicated that at times the material developed by the PEP course of Prem Rawat was repetitive. Moreover, the translation hampered the understanding of the nuances of the original version. As a result, some participants appeared distracted, which required the facilitators to intervene. A review of the workbooks containing the participants' reflections required more time and needed to take place during each session of the workshop, rather than being done at the end of each module. Finally, it was noted that the students need to learn more about, and thus use more frequently, the vocabulary of emotions and feelings. Some answers given in the notebooks differed from the students' verbal communication,

\footnotetext{
${ }^{20} \mathrm{At}$ the end of the project, two workshop presentations and assessment of products (June 19 and $20,2017)$ and a presentation to the citizens were organized. The occasion was the World Day for Cultural Diversity for Dialogue and Development (May 21, 2017). The aim was to show the training work carried out by all groups (high school students, undergraduate students, and teachers).

${ }^{21}$ The presentation of the project, the products made by the participants, and the model of education for peace were presented at a conference organized with the City of Florence. Following this event, the students, teachers, and organizers were invited to the Senate of the Italian Republic.
} 
indicating that the students heard and understood the message, but did not transcribe it accurately.

Those who observed the students during the workshops and at school noticed renewed interest in participating in group work, designing individual outputs, and caring for relationships. Even in this case, however, the students needed more time to design and implement their products, as well as further meetings with experts in communication and development of personal creativity. A further suggested improvement was to extend the experience to the observation of people in everyday life settings, namely, outdoors, and not limit it to a closed venue.

Everyone considered the final days of the course an important opportunity to listen, compare, share, and consolidate their reflections on how issues relating to cultural diversity and peace education (learned and processed within the peer group) offer an opportunity to prevent the radicalization of discriminatory, racist, and xenophobic prejudices and stereotypes. The training path aimed at peace and cultural diversity highlighted how adults could take steps to design educational interventions aimed at raising awareness among young people while developing their intercultural skills and peaceful coexistence, starting from a deeper knowledge of themselves.

This pilot project suggests that the methodologies of peer education and mutual maieutic dialogue are valuable and effective and can be applied in other educational contexts. This will assist in achieving the objective of educating students to develop a sense of inner peace as the first step toward managing conflict and preventing violence - something that should be included in the curricula in educational settings around the world.

\section{References}

Balducci, E. (1985). L'uomo planetario. Brescia, Italy: Camunia.

Bartoloni, S. (2017). Donne di fronte alla guerra: Pace, diritti e democrazia. Bari, Italy: Laterza.

Cambi, F. (2001). Fondamenti interculturali. Roma, Italy: Carocci.

Dolci, D. (1972). Inventare il futuro. Bari, Italy: Laterza.

Freire, P. (1971). Pedagogy of the oppressed. New York, NY: Herder and Herder.

Galeazzi, G. (Ed.). (1992). L'educazione alla pace di Maria Montessori e la pedagogia della pace del '900. Torino, Italy: Paravia.

Galtung, J. (1996). Peace by peaceful means: Peace and conflict, development and civilization. London, UK: Sage.

L'Abate, A. (Ed.). (2001). Giovani e pace: Ricerche e formazione per un futuro meno violento. Torino, Italy: Pangea.

Milanese, F. (1992). La pace come diritto umano. In Pace, diritti dell'uomo, diritti dei popoli, IV, $I$ (pp. 63-77). Padova, Italy: Cedem.

Milani, L. (1967). Lettera a una professoressa. La scuola di Barbiana. Firenze, Italy: Libreria Editrice Fiorentina.

Montessori, M. (1949). Educazione e Pace. Milano, Italy: Garzanti.

Novara, D. (2011). La grammatica dei conflitti . Casale Monferrato, Italy: Edizioni Sonda.

Orefice, P. (2003). Formazione di specie: Per la liberazione del potenziale di conoscenza del sentire e del pensare. Milano, Italy: Guerini Editore. 
Panerai, A., Vitaioli, G., \& Nicola, M. (2012). Manuale di educazione alla pace. Principi, idee, strumenti. Bergamo, Italy: Junior.

Pazzi, A. M. (Ed.). (2018). Luoghi di costruzione: dall'alternanza scuola-lavoro, all'alternanza scuola - comunità. Roma, Italy: Armando.

Pontara, G. (Ed.). (1996). M. K. Gandhi: Teoria e pratica della non-violenza. Milano, Italy: Feltrinelli.

Rawat, P. (2015). Splitting the arrow. Understanding the business of life. Nagano, Japan: Nihon Hicom LTD.

Rosenberg, M. B. (1998). Nonviolent communication. Encinatas (CA): Puddle Dancer Press.

Sclavi, M. (2007). Costruire una pace. Milano, Italy: Bruno Mondadori.

Open Access This chapter is licensed under the terms of the Creative Commons Attribution 4.0 International License (http://creativecommons.org/licenses/by/4.0/), which permits use, sharing, adaptation, distribution and reproduction in any medium or format, as long as you give appropriate credit to the original author(s) and the source, provide a link to the Creative Commons license and indicate if changes were made.

The images or other third party material in this chapter are included in the chapter's Creative Commons license, unless indicated otherwise in a credit line to the material. If material is not included in the chapter's Creative Commons license and your intended use is not permitted by statutory regulation or exceeds the permitted use, you will need to obtain permission directly from the copyright holder.

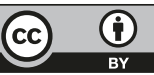

